\title{
Underpresentation of shortness of breath in the general population: Results of the DIMCA programme
}

\author{
G. van den Boom, P.R.S. Tirimanna, A.A. Kaptein, I. Mesters, C.L.A. van Herwaarden, R.P. Akkermans, \\ C. van Weel and C.P. van Schayck
}

\begin{abstract}
Objectives: To investigate the extent of underpresentation of shortness of breath to general practitioners (GPs) in a random sample of the general population without a confirmed diagnosis of obstructive airways disease (OAD). A second objective was to assess the influence of a person's perception of symptoms and psychological factors as possible causes for underpresentation.
\end{abstract}

Design: A random sample of the general population $(n=1155)$ was screened for respiratory symptoms. Of those who experienced shortness of breath at some stage during the preceding year, the ability to perceive dyspnoea was assessed in 134 patients, by means of a Borg score and a visual analogue scale (VAS) during each step of a histamine provocation test. A psychological profile was assessed in 130 subjects using five validated questionnaires.

Patients: Two random sample groups ( $n=134$ and $n=130$ ) of adults reporting dyspnoea without a diagnosis of OAD.

Results: Of the initial sample, 285 (25\%) had experienced shortness of breath in the year preceding the screening: only 93/285 (33\%) had ever consulted their GP for this. Multivariate analysis showed that neither a person's perception of dyspnoea nor psychological factors could explain underpresentation. Conclusions: Underpresentation of symptoms is a major factor contributing to underdiagnosis of OAD, but this is not related to the patient's perception of symptoms nor to their psychological profile.

\section{INTRODUCTION}

As with many chronic diseases, a significant proportion of the general population has obstructive airways disease (OAD) which is undiagnosed by the GP. Comparison of the number of diagnosed cases from morbidity registration systems with the results of population surveys indicates that the discrepancy may be as much as ten-fold. ${ }^{1-4}$ The GP has generally been blamed for this underdiagnosis; ${ }^{5}$ however, it is likely that underpresentation of respiratory symptoms by the patient may also contribute. The early symptoms of $\mathrm{OAD}$ are often non-specific and may be ignored, and the condition may worsen so gradually that patients adapt to it.

In the Detection, Intervention and Monitoring of COPD and Asthma (DIMCA) programme, patients without a confirmed diagnosis of OAD, but with early signs of $\mathrm{OAD}$, were detected by means of a two-stage programme consisting of screening followed by monitoring for up to two years. The details of this study have been published elsewhere; ${ }^{6,7}$ the results confirm that there is a significant level of underpresentation. A large proportion (74\%) of subjects with respiratory problems during the year preceding the screening never consulted a GP for this, regardless of the severity. Of the subjects with persistently reduced lung function or increased levels of bronchial hyperresponsiveness and reversibility, $69 \%$ did not seek medical help. ${ }^{7}$ Poor perception of symptoms may be a possible explanation of underpresentation. ${ }^{8-10}$

In our opinion, shortness of breath is the core alarm symptom of asthma. Other symptoms, such as cough and phlegm production, are less specific. The aim of this study was to determine the prevalence of shortness of breath in the general population and the extent to which this was reported to a GP. The second aim was to assess the extent to which perception of symptoms and psychological factors explain the underpresentation of shortness of breath.

\section{METHODS}

\section{Design}

This study is part of the DIMCA programme, which aimed to assess the efficacy and cost-effectiveness of active detection and early treatment of OAD. ${ }^{6}$ The programme consisted of detection and treatment phases. A random sample of undiagnosed adult subjects from the general population $(n=1155)$, aged between 25 and 70 years, were invited for screening, consisting of a standardised respiratory symptoms questionnaire and lung function assessment. Subjects with symptoms or objective signs of OAD or both, were invited to participate in the second stage of the detection phase: the monitoring. In this phase, lung function and symptoms were measured every three months for up to two years, during which patients were selected for the treatment phase.

As part of the screening, subjects were asked whether they had experienced shortness of breath during the preceding 12 months and, if so, whether they had consulted their GP or chest physician for this. Two random samples of those reporting shortness of breath were studied further: one $(n=134)$ to assess an individual's ability to perceive shortness of breath; the other $(n=130)$ to assess the role of psychological factors in relation to medical consultation.

\section{Patient characteristics}

The characteristics of patients who experienced shortness of breath during the year preceding the screening were compared with those who did not. Within the group reporting shortness of breath, the characteristics of those who did and did not consult their GP were compared. The VC, FVC, FEV 1 and reversibility were measured using a portable Microspiro HI-298 (Chest Corporation, Tokyo, Japan). ${ }^{11}$ After instruction, subjects were asked to perform three unforced and three forced expiratory manoeuvres from maximum inspiration. The FEV corresponding to the manoeuvre with the highest sum of the $\mathrm{FEV}_{1}$ and $\mathrm{FVC}$ was recorded as the $\mathrm{FEV}_{1}$ at that moment. Predicted values were calculated using
Guido van den Boom Research Coordinator

Prasanna Tirimanna Research Coordinator

Reinier Akkermans Statistician

Chris van Weel Professor in General Practice

Onno van Schayck Professor in Preventive Medicine

Department of General Practice and Social Medicine, University of Nijmegen, PO Box 9101, 6500 HB Nijmegen, The Netherlands.

Ad Kaptein

Medical Psychologist

Department of Psychiatry, Medical Psychology, University of Leiden, The Netherlands.

Ilse Mesters

Senior Lecturer

Department of Health Education, University of Maastricht, The Netherlands.

Cees van Herwaarden Professor in Pulmonology

Department of Pulmonology

'Dekkerswald', University of Nijmegen, The Netherlands.

Correspondence to: Dr G. van den Boom

Date received: 05/10/98 Date accepted: 01/02/99

Asthma in Gen Pract 1999; 7(1): 3-7. 
the equations by Quanjer et al. ${ }^{12}$ The degree of reversibility was measured as the change in $\mathrm{FEV}_{1}$ relative to the predicted value after salbutamol administration. Current smoking, smoking history and the number of pack-years were assessed during the screening.

\section{Perception and medical consultation}

Perception of shortness of breath was assessed during a histamine provocation test. ${ }^{13}$ Patients were instructed to record their experienced level of shortness of breath 30 seconds after each dose of histamine and immediately before the $\mathrm{FEV}_{1}$ measurement. The extent of shortness of breath was rated on a vertically oriented modified Borg scale, with a 12-point ordinal scale ranging from 0 (no breathlessness at all) to 0.5 (very, very slight breathlessness) to 10 (maximum breathlessness), ${ }^{13,14}$ and on an anchorless 100-mm visual analogue scale (VAS). ${ }^{15}$

Table 1: Clinical characteristics of patients who experienced shortness of breath in the year preceding the screening $(n=285)$ compared with the rest of the screened sample $(n=870)$

\begin{tabular}{lccr} 
Variable & Shortness of breath & No shortness of breath & p value \\
\hline FEV 1 (ml) & 2997 & 3320 & $<0.01$ \\
FEV $1 \%$ pred & $91.9(90.1-93.7)$ & $98.5(97.6-99.4)$ & $<0.01$ \\
VC (ml) & 3827 & 4149 & $<0.01$ \\
Reversibility (\%) & $4.1(3.5-4.7)$ & $3.0(2.8-3.2)$ & $<0.01$ \\
Pack-years & 9.6 & 7.6 & 0.01 \\
Current smokers (\%) & 47.0 & 33.9 & $<0.01$ \\
Ex-smokers (\%) & 31.6 & 35.5 & 0.23 \\
Gender (\% female) & 59.7 & 53.9 & 0.09 \\
Age & 44.5 & 43.4 & 0.14
\end{tabular}

$\mathrm{FEV}_{1}$, forced expiratory volume in $1 \mathrm{~s} ; \mathrm{FEV}_{1} \%$ pred, $\mathrm{FEV}_{1}$ as percentage of the predicted value; VC, vital capacity

NB: Reversibility defined as $\%$ change in $\mathrm{FEV}_{1}, 15 \mathrm{~min}$ after inhalation of $800 \mu \mathrm{g}$ salbutamol; $(95 \% \mathrm{Cl})$

Table 2: Clinical characteristics of patients who experienced shortness of breath in the year preceding the screening and who consulted their GP $(n=93)$ compared with those who did not $(n=189)^{a}$

\begin{tabular}{lccc} 
Variable & Did consult GP & Did not consult GP & $p$ value \\
\hline FEV $_{1}(\mathrm{ml})$ & 3056 & 2972 & 0.41 \\
FEV $_{1} \%$ pred & $89.8(86.6-93.0)$ & $93.0(90.8-95.2)$ & 0.11 \\
VC (ml) & 3954 & 3759 & 0.13 \\
Reversibility (\%) & $5.5(3.9-7.1)$ & $3.5(2.9-4.1)$ & 0.01 \\
Pack-years & 9.6 & 9.7 & 0.93 \\
Current smokers (\%) & 45.2 & 47.9 & 0.66 \\
Ex-smokers (\%) & 36.6 & 29.2 & 0.21 \\
Gender (\% female) & 59.1 & 59.8 & 0.92 \\
Age & 41.9 & 45.8 & 0.01
\end{tabular}

${ }^{a}$ Three subjects answered do not know/do not want to tell

$F E V_{1}$, forced expiratory volume in $1 \mathrm{~s} ; \mathrm{FEV}_{1} \%$ pred, $\mathrm{FEV}_{1}$ as percentage of the predicted value; VC, vital capacity

NB: Reversibility defined as \% change in $\mathrm{FEV}_{1}, 15 \mathrm{~min}$ after inhalation of $800 \mu \mathrm{g}$ salbutamol; (), $95 \% \mathrm{Cl}$
Psychological factors and medical consultation The following five validated questionnaires were completed:

1. The Utrecht Coping List (UCL), ${ }^{17}$ of which the first four scales (Active tackling, Palliative responses, Avoidance, and Seeking social support) were used

2. The State-Trait Anxiety Inventory ${ }^{18}$

3. Multidimensional Health Locus of Control Scale, which assesses perceived causes of health and illness ${ }^{19}$

4. The Respiratory Illness Opinion Survey, which assesses attitudes of patients with respiratory disorders towards their illness. ${ }^{20}$ Two subscales Optimism and Stigma, were used

5. The Dutch Personality Inventory, of which only the subscale Inadequacy (neuroticism) was measured by means of a questionnaire completed by the patients themselves. ${ }^{21}$

\section{Analysis}

Differences between patient characteristics were tested with independent Student's $t$ tests. The proportions of men to women and smokers to non-smokers were tested by $\chi^{2}$ tests. The association between a perception of symptoms and medical consultation was assessed by a logistic regression analysis, with consultation with a doctor $(0=$ no, $1=$ yes $)$ as the dependent variable. Perception of symptoms was defined as the difference in Borg (VAS) score [the last Borg (VAS) score minus the baseline Borg (VAS) score]. A large difference would indicate good perception; no difference, despite a decrease in $\mathrm{FEV}_{1}$, would indicate poor perception. The difference in Borg (VAS) entered the equation as an explanatory or independent variable. The change in $\mathrm{FEV}_{1}$ during histamine provocation, baseline Borg (VAS), baseline $\mathrm{FEV}_{1}$ and age were entered as covariates in the analysis. All possible interaction effects (multiplicative) were also entered in the model. In the case of a non-interaction model, the results from the reduced model (for example, without the interaction terms) were presented. A forward procedure to enter the variables in the equation was used: inclusion of variables was based on a likelihood function (SPSS 6.0 for Windows: Logistic Regression; Forward Likelihood). In a second analysis, perception was dichotomised. Subjects who had a difference in Borg (VAS) score equal to zero, in spite of a decrease in $\mathrm{FEV}_{1}$, were labelled 'non-perceivers' whereas the remainder of the sample was labelled 'perceiver'. The association between psychological factors and medical consultation was assessed in a similar way by logistic regression analysis. In this analysis, whether or not a doctor was consulted was entered into the analysis as the dependent variable, and the scale scores from the psychological tests were entered as independent variables, including all one-by-one interaction terms (multiplicative).

\section{RESULTS}

Underpresentation of shortness of breath in the general population

Of all subjects screened 285/1155 (24.7\%) had experienced shortness of breath during the year preceding the screening. These subjects had a significantly lower FEV , indicating airways obstruction. This difference remained after 
correction for age, gender and height $\left(\mathrm{FEV}_{1}\right.$ expressed as percentage of the predicted value). Subjects with shortness of breath had a smaller vital capacity and a higher level of reversibility after inhalation of salbutamol. They had significantly more pack-years and were more often currently smokers (Table 1). Although they experienced shortness of breath at least once, only 93/285 $(32.6 \%)$ had ever consulted a GP for this. Those who consulted their GP had a higher level of reversibility and were four years younger, on average, than those who did not, but there were no significant differences in $\mathrm{FEV}_{1}$ expressed as a percentage of the predicted value or vital capacity nor in smoking status or gender (Table 2).

\section{Poor perception as possible cause of underpresentation}

In the first sample $(n=134)$, perception of shortness of breath was assessed during a histamine provocation test. The change in $\mathrm{FEV}_{1}$ induced by the test was normally distributed with an average of $-18 \%$ (SD 10\%). Most subjects (72\%) had a decrease in $\mathrm{FEV}_{1}$ greater than $10 \%$. In this subgroup, $51(38.1 \%)$ had consulted a GP for respiratory symptoms, a percentage similar to that in the whole group. The results from the logistic regression model showed that a person's perception was unlikely to be a significant factor in his decision to seek medical help. Perception, defined as the difference in Borg scores, was not statistically significantly different $(p=0.51)$ between those who consulted a GP and those who did not (Table 3). As expected, a person's perception of symptoms correlated well with the decrease in $\mathrm{FEV}_{1}$ induced (the greater the induced dyspnoea, the larger the perceived difference in dyspnoea). However, none of the covariates reached the level of statistical significance. The result was similar using the VAS scores: neither perception of symptoms nor any of the covariates in the model played a significant role in medical consultation. Table 4 presents the results from the dichotomised analysis: 23 subjects indicated that they did not perceive shortness of breath in spite of a decrease in $\mathrm{FEV}_{1}$, induced by histamine, while the remaining 111 subjects did perceive the induced dyspnoea, to some extent. Only $22 \%$ of the non-perceivers consulted their GP compared with $41 \%$ of those who did perceive symptoms. This almost two-fold difference approached statistical significance $(p=0.08)$; the associated odds ratio was 2.55 .

\section{Psychological factors as possible causes of underpresentation}

A second sample was studied to determine whether psychological factors were associated with seeking medical help. Despite randomisation, a smaller proportion $(20.8 \%)$ of this group had consulted their GP than in the whole group. None of the psychological instruments showed significant differences between those who did and did not consult a GP for shortness of breath. Univariate testing of the differences produced similar results, indicating that correction for partial correlations did not influence the outcome. All differences between the two groups were very small (the effect sizes ranged from 0.09 to 0.30 ).

\section{DISCUSSION}

Increasing attention has been paid in recent years to preventing underdiagnosis of asthma and COPD. The development of guidelines for diagnosis and therapy of asthma are examples of efforts in this

Table 3: Association between perception of shortness of breath and medical consultation due to shortness of breath: Results of logistic regression analysis

\begin{tabular}{|c|c|c|c|}
\hline Variables & B & Standard error & $p$ \\
\hline \multicolumn{4}{|l|}{ Dependent variable } \\
\hline \multicolumn{4}{|l|}{ Consultation ( $0=$ no; $1=$ yes) } \\
\hline \multicolumn{4}{|l|}{ Main effect } \\
\hline Difference in Borg score & 0.09 & 0.13 & 0.51 \\
\hline \multicolumn{4}{|l|}{ Covariates } \\
\hline Percentage change in FEV & -3.27 & 1.96 & 0.09 \\
\hline Baseline Borg score & 0.14 & 0.17 & 0.40 \\
\hline Baseline FEV & $<0.01$ & $<0.01$ & 0.43 \\
\hline Age & $<-0.01$ & 0.02 & 0.60 \\
\hline \multicolumn{4}{|l|}{ Dependent variable } \\
\hline \multicolumn{4}{|l|}{ Consultation ( $0=$ no; $1=y e s)$} \\
\hline \multicolumn{4}{|l|}{ Main effect } \\
\hline Difference in VAS score & 0.01 & 0.01 & 0.34 \\
\hline \multicolumn{4}{|l|}{ Covariates } \\
\hline Percentage change in FEV & -3.26 & 1.92 & 0.09 \\
\hline Baseline VAS score & 0.01 & 0.01 & 0.38 \\
\hline Baseline FEV & $<0.01$ & $<0.01$ & 0.31 \\
\hline Age & -0.01 & 0.02 & 0.75 \\
\hline
\end{tabular}

Table 4: Perception of shortness of breath as determined by GP consultation

\begin{tabular}{lrrr} 
& Did consult GP & Did not consult GP \\
\hline Did not perceive & $5(22 \%)$ & $18(78 \%)$ & $23(100 \%)$ \\
Did perceive & $46(41 \%)$ & $65(59 \%)$ & $111(100 \%)$ \\
& $51(38 \%)$ & $83(62 \%)$ & $134(100 \%)$
\end{tabular}

$\chi^{2}=3137 ; p=0.08 ;$ odds ratio $=2.55$

Table 5: Association between psychological factors and medical consultation due to shortness of breath: Results of logistic regression analysis

\begin{tabular}{lrrr} 
Factors & B & Standard error & $p$ \\
\hline $\begin{array}{l}\text { Dependent variable: } \\
\text { Consultation (0=no; 1=yes) }\end{array}$ & & & \\
Main effect: & & & \\
$\quad$ Utrecht Coping List & & & \\
$\quad$ Active tackling & -0.08 & 0.09 & 0.37 \\
$\quad$ Palliative responses & -0.10 & 0.13 & 0.45 \\
$\quad$ Avoidance & 0.01 & 0.09 & 0.92 \\
$\quad$ Seeking social support & -0.01 & 0.18 & 0.99 \\
$\quad$ State-Trait Anxiety Inventory & & & \\
$\quad$ State-anxiety & 0.01 & 0.07 & 0.84 \\
Multidimensional Health Locus of & & & \\
Control Scale & & & \\
$\quad$ Internal & 0.03 & 0.07 & 0.67 \\
$\quad$ External & 0.06 & 0.08 & 0.49 \\
$\quad$ Chance & 0.11 & 0.08 & 0.15 \\
Respiratory IIIness Opinion Survey & & & \\
$\quad$ Optimism & -0.08 & 0.10 & 0.44 \\
$\quad$ Stigma & -0.01 & 0.05 & 0.82 \\
Dutch Personality Inventory & & & \\
$\quad$ Inadequacy & 0.05 & 0.04 & 0.24
\end{tabular}


respect. This is particularly important as there is evidence that the irreversible loss of lung function can be minimised by initiating proper treatment at an early stage. ${ }^{22}$ However, when there are patients who are currently undiagnosed, screening may be the only option to significantly reduce underdiagnosis. Our study revealed that a substantial proportion of the adult general population had shortness of breath and only a few of these consulted a GP for this; raising the question of whether patients were able to perceive dyspnoea. Most patients did perceive the increase in airway obstruction induced by histamine, but this varied among patients and was related to the level of induced obstruction. There was no difference, however, in the level of perceived shortness of breath, corrected for covariates, between those who did and those who did not consult their GP. Analysis of the Borg and the VAS ratings of perceived shortness of breath produced nonsignificant results. From this, it can be concluded that the level of perception of dyspnoea is unlikely to be a significant cause for underpresentation and hence underdiagnosis. In a dichotomised analysis, non-perceivers had consulted their GP less frequently, but this difference was not statistically significant.

If underpresentation cannot be explained by differences in perception, personal psychological characteristics, such as the extent of coping or the anxiety aroused by a symptom, might offer an explanation. However, a number of psychological tests all failed to reveal differences between the two groups and the effect sizes were very small, indicating that the psychological profiles of the subjects who did and did not consult the GP were similar. The analysis had limited statistical power because of the uneven distribution of medical consultation ( $21 \%$ vs $79 \%$ of the sample), but it is unlikely that a more even distribution would have led to significant results.

Age and reversibility were the only two characteristics that were significantly different between those who did and those who did not consult a GP. The average age of those who consulted their GP for shortness of breath was lower, whereas in general, consultation frequency rose with age. An explanation for this paradoxical result might be that the interpretation of the seriousness of the symptom is different among different age groups. Elderly people may interpret shortness of breath as a natural consequence of ageing and underestimate its seriousness. It is not surprising that reversibility was a significant factor as an earlier study demonstrated that medical consultation was significantly associated with airway variability and a diminished quality of life. ${ }^{7}$

The positive predictive value of shortness of breath for respiratory disease is crucial to the interpretation of these results. The DIMCA data confirmed that shortness of breath may indeed be considered a core alarm symptom: $83 \%$ of all monitored patients with shortness of breath complied with criteria for early treatment at some stage during the monitoring. Thirty-four patients $(22 \%)$ with shortness of breath fulfilled criteria for mild-to-moderate asthma or
COPD. Another 28 patients (18\%) with shortness of breath showed a rapid decline in $\mathrm{FEV}_{1}$ during the monitoring ( $>80 \mathrm{ml} /$ year.), with increased levels of reversibility and/or bronchial hyperresponsiveness. Furthermore, 62 patients (41\%) with shortness of breath showed an accelerated decline in $\mathrm{FEV}_{1}$ (> $80 \mathrm{ml} / 2$ years) with mild objective signs of reversibility or bronchial hyperresponsiveness. Only $17 \%$ of patients who reported shortness of breath during the year preceding the screening did not meet the above criteria.

In order to reduce underdiagnosis, GPs should be aware that a substantial proportion of subjects have unreported asthma symptoms. Medical consultation is not associated with either perception of these symptoms or with individual psychological factors. Patients are more likely to consult their GP when the condition affects their normal daily activities or the variability of the airways exceeds a certain level, often in an advanced stage of disease. Consequently, early diagnosis may be possible only by means of active case-finding or screening strategies.

\section{References}

1. Speight ANP. Is asthma being underdiagnosed and undertreated? BMJ 1978; 11: 331-2.

2. Jones DT, Sears MR, Holdaway MD, et al. Childhood asthma in New Zealand. Br J Dis Chest 1987; 81: 332-40. 3. Hoogen HJM, Huygen FJA, Schellekens JWG, et al. Morbidity figures from general practice. Nijmegen: Nijmeegs Universitair Huisartsen Instituut, 1992.

4. Royal College of General Practitioners, Office of Population Censuses and Surveys, Department of Health and Social Security. Morbidity statistics from general practice 1981-82. Third national study. London: HMSO, 1986.

5. Levy M. Delay in diagnosing asthma - Is the nature of general practice to blame? J R Coll Gen Pract 1986; 36: $52-3$

6. van den Boom G, van Schayck CP, Rutten-van Molken MPMH, et al. Active detection of COPD and asthma in the general population: Results and economic consequences of the DIMCA program. Am J Respir Crit Care Med 1998; 158(6): $1730-8$

7. van den Boom G, Rutten-van Molken MPMH, Tirimanna PRS, et al. Association between health-related quality of life and consultation for respiratory symptoms: Results from the DIMCA programme. Eur Respir J 1998; 11: 67-72.

8. Barnes PJ. Poorly perceived asthma. Thorax 1992; 47: 408-9.

9. Kendrick AH, Hoggs CMB, Whitfield MJ, et al. Accuracy of perception of severity of asthma: Patients treated in general practice. BMJ 1993; 307: 422-4.

10. Brand PLP, Rijcken B, Schouten JP, et al. Perception of airways obstruction in a random population sample:

Relationship to airways hyperresponsiveness in the absence of respiratory symptoms. Am Rev Respir Dis 1992; 146: 396-401. 11. Dompeling E, van Schayck CP, Folgering $\mathrm{H}$, et al. Accuracy, precision and linearity of the portable flow-volume meter Microspiro HI-298. Eur Respir J 1991; 4: 612-5. 12. Quanjer PH, Tammeling GJ, Cotes JE, et al. Lung volumes and forced ventilatory flows. Official statement of the European Respiratory Society. Eur Respir J 1993; 6 (Suppl 16): $5-40$.

13. Cockcroft DW, Killian DN, Mellon JJA, et al. Bronchial reactivity to inhaled histamine; a method and clinical survey. Clin Allergy 1977; 7: 237-43.

14. Borg GAV. Psychophysical bases of perceived exertion. Med Sci Sports Exercise 1982; 14: 377-81.

15. Burdon JGW, Juniper EF, Killian KJ, et al. The perception of breathlessness in asthma. Am Rev Respir Dis 1982; 126: $825-8$.

16. Wilson RC, Jones PW. A comparison of the visual analogue scale and modified Borg scale for the measurement of dyspnoea during exercise. Clin Sci 1989: 76: 277-82. 
17. Scheurs PJG, van de Willege G, Tellegen B, et al. Utrechtse Coping Lijst. Lisse: Swets \& Zeitlinger, 1988.

18. van der Ploeg HM, Defares PB, Spielberger CD. The Dutch version of the Spielberger State-Trait Anxiety Inventory, STAI$D Y$. Lisse: Swets \& Zeitlinger, 1980.

19. Wallston KA, Wallston BS, DeVellis RF. Development of the Multidimensional Health Locus of Control Scales. Health Education Monographs 1978; 6: 160-70.
20. Kaptein AA. Psychological correlates of length of hospitalization and rehospitalization in acute severe asthma. Soc Science Med 1982; 16: 725-9.

21. Luteijn F, Starren J, Van Dijk H. Nederlandse Persoonlijkheids Vragenlijst. Lisse: Swets \& Zeitlinger, 1985.

22. Haahtela T, Jarvinen M, Kava T, et al. Comparison of a $B_{2}-$ agonist, terbutaline, with an inhaled corticosteroid, budesonide, in newly detected asthma. N Engl J Med 1994; 331: 700-5.

\title{
A randomised trial of the initiation of asthma treatment
}

\author{
A.H. Morice and M.E. Taylor
}

\begin{abstract}
Objective: To compare the effectiveness of four classes of anti-asthma medication as initial treatment in a randomised open study in an asthma clinic setting.
\end{abstract} Design and subjects: Eighty-six patients aged 16-70 years were recruited into an open trial following informed consent. The diagnosis of asthma was established by either a $15 \%$ diurnal variability in peak expiratory flow (PEF) or a $>15 \%$ bronchodilation to inhaled salbutamol. Patients were randomised to one of the following drug classes: a short-acting $\beta_{2}$-agonist $(n=21)$; an inhaled steroid $(n=25)$; nedocromil sodium $4 \mathrm{mg}$ qds $(n=22)$; and oral theophylline $(n=18)$. Symptoms and daily PEF measurements were recorded on a diary record card. Results: Baseline characteristics of the four groups

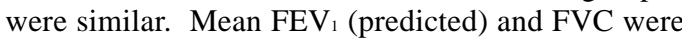
$2.61(82 \%)$ and $3.61(91 \%)$, respectively. Wheeze, cough and expectoration were present on 4.2, 3.8 and 2.8 days per week. At one month, the greatest improvement in number of symptom-free days was seen in the group taking the inhaled steroids. Mean days per week with wheeze fell by $1.3(p<0.05)$, cough by 0.5 (NS) and expectoration by 1.5 $(p<0.05)$. Nedocromil sodium produced a mean decrease in symptom days of $0.8,0.3$ and 0.8 , respectively (NS). Other modalities of treatment produced no significant change in symptoms. Mean improvement in $\mathrm{FEV}_{1}$ was greatest in the steroid group $(11 \% ; p<0.02)$ followed by nedocromil sodium $(9 \% ; p<0.02)$. There was no change with short-acting $\beta_{2}$-agonists or theophylline.

Conclusions: Initiation of treatment with antiinflammatory therapy produces the greatest symptomatic and physiological improvement in mild asthma.

\section{INTRODUCTION}

Therapy for asthma shows wide variation between countries. ${ }^{1}$ In part, this is due to health economics with cheaper medications, such as theophyllines, being widely prescribed in developing countries. Even in countries with sophisticated healthcare, there are considerable differences in prescribing practices for the newly diagnosed person with asthma. ${ }^{2}$
Our increased understanding of the chronic inflammatory nature of asthma has led some authorities to advocate the use of anti-inflammatory drugs in first-line management. ${ }^{3}$ In the UK, despite widespread knowledge and acceptance of guidelines recommending the early use of steroids in adults, $\beta_{2}$-agonist bronchodilator therapy alone is still the most widely used first-line treatment. ${ }^{2}$

The objective of asthma management is to improve the quality of life for patients by abolition of symptoms, improvement of lung function, and reduction of severity and frequency of exacerbations. ${ }^{4}$ As the majority of asthmatics are in the mild-to-moderate category, the first choice of antiasthma medication is important both in terms of achieving these objectives and providing costeffective care. In this study we have examined the short-term response of the commonly prescribed asthma medications in a 'real-life' study conducted in a nurse-run asthma clinic designed to be as similar as possible to that seen in primary healthcare.

\section{METHOD}

The trial was approved by the Local Ethics Committee. Patients with mild-to-moderate asthma were recruited by direct referral from interested general practitioners or from hospital departments. Some patients were seen as self-referrals and were randomised after contact with their GP. Only patients not currently taking anti-asthma therapy were recruited. Previous occasional use of $\beta_{2}-$ agonist bronchodilators did not preclude entry into the study.

The diagnosis of asthma was established by the demonstration of one of the following:

- A $15 \%$ diurnal variability in PEF over one week;

- A > 15\% increase in FEV 1 with salbutamol $200 \mu \mathrm{g}$ from a metered dose inhaler;

- A reproducible fall of $15 \%$ in PEF caused by exposure to a precipitating factor.

Informed consent was obtained on the initial visit. Patients were assessed by computerised questionnaire
Alyn Morice

Head of Academic

Department of Medicine

Marion Taylor

Research Nurse

Academic Department of Medicine, University of Hull, Castle Hill Hospital, Castle Road, Cottingham, Hull HU16 5JQ, UK.

Correspondence to: Professor A.H. Morice

Date received: 02/10/98 Date accepted: 15/02/99

Asthma in Gen Pract 1999; 7(1): 7-9. 